\title{
M-learning: o uso de dispositivos móveis por uma geração conectada
}

\author{
M-learning: the use of mobile devices by a connected generation \\ M-learning: el uso de dispositivos móviles por una generación conectada
}

\author{
ANNA HElEna Silveira SONEgO ${ }^{1}$ \\ Patricia AleJandRa BEHAR (10 ${ }^{1}$ \\ ${ }^{1}$ Universidade Federal do Rio Grande do Sul, Porto Alegre, RS, Brasil.
}

\begin{abstract}
RESUMO
Este artigo tem por objetivo analisar a construção de aplicativos educacionais a fim de auxiliar no desenvolvimento do m-learning. Essa modalidade surgiu pela necessidade de planejar e implementar o uso crítico dos dispositivos móveis na educação, principalmente, por uma geração conectada em rede. A metodologia adotada foi uma abordagem qualitativa e quantitativa, do tipo estudo de caso, com estudantes de turmas de graduação de uma universidade pública. Na coleta de dados, foram disponibilizados dois instrumentos: a observação participante e o questionário com perguntas abertas e fechadas. Os dados permitiram verificar que o m-learning pode contribuir significativamente no processo de ensino e de aprendizagem dos estudantes. Nesse contexto, destaca-se o potencial para promover inovações no meio escolar, novas formas de comunicação, de interação e novas possibilidades para compreensão de conteúdos escolares através de aplicativos.
\end{abstract}

Palavras-chave: M-Learning. Aplicativos. Geração conectada.

\begin{abstract}
This article aims to analyze the construction of educational applications in order to assist in the development of m-learning. This modality arose from the need to plan and implement the critical use of mobile devices in education, mainly by a networked generation. The methodology adopted was a qualitative and quantitative approach, of the case study type, with undergraduate students from a public university. In the data collection, two instruments were made available: the participant observation and the questionnaire with open and closed questions. The data allowed to verify that the m-learning can contribute significantly in the process of teaching and learning of the students. In this context, we highlight the potential to promote innovations in the school environment, new forms of communication, interaction and possibilities for understanding school content through applications.
\end{abstract}

Keywords: M-learning. Applications. Generation Connected.

\section{RESUMEN}

Este artículo pretende analizar la construcción de aplicaciones educativas para ayudar en el desarrollo del m-learning. Esta modalidad surgió de la necesidad de planificar e implementar el uso crítico de dispositivos móviles en la educación, principalmente por una generación en red. La metodología adoptada fue un enfoque cualitativo y cuantitativo, del tipo de estudio de caso, con estudiantes universitarios de una universidad pública. En la recopilación de datos, se pusieron a disposición dos instrumentos: la observación participante y el cuestionario con preguntas abiertas y cerradas. Los datos permitidos para verificar que el m-learning puede contribuir significativamente en el proceso de enseñanza y aprendizaje de los estudiantes. En este contexto, destacamos el potencial para promover innovaciones en el entorno escolar, nuevas formas de comunicación, interacción y posibilidades para comprender el contenido escolar a través de aplicaciones.

Palabras clave: M-Learning. Aplicaciones. Generación conectada. 


\section{INTRODUÇÃo}

No contexto da atual sociedade considera-se que existe um aumento significativo de usuários, dentre eles estudantes, que utilizam smartphones e tablets. Com base nessa circunstância, é importante refletir como o seu uso pode influenciar e possibilitar o desenvolvimento da aprendizagem móvel. Essa permite a realização de atividades de estudo, com vistas a ampliar a comunicação, a produção de conteúdo e o compartilhamento de informações em qualquer lugar e a qualquer hora. Diante desse cenário, objetiva-se, neste estudo, analisar a construção de aplicativos educacionais a fim de auxiliar o desenvolvimento do m-learning através do uso dos dispositivos móveis. Portanto, a escolha do público e do presente tema está atrelada à atual geração, que está presente nas escolas e usuária recorrente desses dispositivos. Trata-se de alunos que convivem diariamente com seus smartphones e, consequentemente, levam-nos para a sala de aula. O uso desses aparelhos permite ampliar as redes de comunicação, informações e de construção de conteúdo como textos, vídeos, áudios, editor de fotos, entre outras funções. Porém, o equipamento por si só não garante tais fins, para isso é necessário o uso de metodologias e estratégias por parte dos professores. Diante dessa circunstância, acreditase que os professores podem disponibilizar atividades de estudo, explorando smartphones e tablets como um recurso tecnológico. Nesse sentido, é relevante que os futuros docentes estejam preparados para interagir com esse público nas escolas. Desse modo, os cursos de graduação, mais especificamente de licenciaturas, devem oportunizar aos seus alunos momentos para vivenciar, experimentar e desafiarem-se com esses aparelhos, a fim de desenvolverem novas formas de aprendizagens.

Observa-se que essa demanda na formação vem acompanhando o desenvolvimento das tecnologias digitais nos últimos anos, mais especificamente com o uso dos smartphones e tablets. Estes têm se fortalecido de modo acelerado na sociedade, no cotidiano, disseminando-se em outros âmbitos, como no educacional. De acordo com os dados da Conferência das Nações Unidas sobre Comércio e Desenvolvimento (UNCTAD), o Brasil ocupa o quarto lugar no ranking mundial de usuários de internet, representado por 120 milhões de pessoas conectadas. Desse modo, o Brasil fica atrás apenas dos Estados Unidos, com 242 milhões; a Índia, 33 milhões e a China, 705 milhões (ORGANIZAÇÃO DAS NAÇÕES UNIDAS DO BRASIL, 2017). Essa expansão deve-se ao fato dos brasileiros, ou seja, mais de 100 milhões de pessoas, já estarem conectados com a internet, compartilhando e produzindo conhecimento e distribuindo informações. Entretanto, ainda existem países menos desenvolvidos em que o uso da internet banda larga é limitado, devido o seu custo ser alto para a maioria da população (ONUBR, 2017). Destaca-se, também, que essa situação está em conformidade com a facilidade de manuseio e acesso à internet que esses aparelhos oferecem, otimizando a portabilidade e a mobilidade. Para o desenvolvimento das proposições enunciadas, apresenta-se a organização do trabalho em cinco seções. Na primeira, são abordados os conceitos sobre a aprendizagem móvel, os dispositivos e a utilização de aplicativos. Na segunda seção, é mostrado o processo de formação de professores para atender uma geração conectada à internet. Na terceira, são descritos os procedimentos metodológicos deste estudo. $\mathrm{Na}$ quarta, são elencados os resultados obtidos a partir dos instrumentos de pesquisa e da construção dos aplicativos. Na quinta e última seção, as considerações finais mostram as contribuições que os dispositivos móveis podem apresentar quando utilizados na educação como um recurso tecnológico.

\section{M-LEARNING: Dispositivos Móveis E APLICATIVOS}

Compreende-se que o m-learning, ou seja, a aprendizagem móvel (na tradução livre) incorpora o uso das tecnologias móveis separadas ou em combinação com outras tecnologias digitais (ORGANIZAÇÃO DAS NAÇÕES UNIDAS PARA A EDUCAÇÃO, CIÊNCIA E CULTURA, 2014). Essa aprendizagem pode ocorrer dentro ou fora da sala de aula. Conforme Quinn (2000), o m-learning pode ser considerada uma intersecção do computador móvel e a e-learning ${ }^{1}$ em que os dispositivos podem potencializar a aprendizagem, tendo em vista que se fazem presente na escola através dos estudantes ou da própria instituição. Para o desenvolvimento desse tipo de aprendizagem, torna-se primordial que ela seja orientada por um professor ou responsável pelas atividades. Conforme Leite (2014, p. 5), a aprendizagem móvel pode ser entendida como:

uma aprendizagem que ocorre quando o estudante não está em um local estático e estipulado, ou no momento em que a aprendizagem acontece quando o estudante tira vantagem das oportunidades de aprendizagem oferecidas por tecnologias móveis (LEITE, 2014, p.5).

Sendo assim, essa aprendizagem é vista como uma possibilidade de mediar atividades de estudo em qualquer modalidade ou nível de ensino a partir do uso dos dispositivos móveis. Acerca desse termo, existem muitas discussões em nível mundial, que abordam que, dentre os

\footnotetext{
$1 \mathrm{O}$ e-learning pode ser visto como uma nova versão da EAD na qual as atividades são mediadas pelas tecnologias digitais de informação e comunicação (VALENTE, 2014).
} 
dispositivos, devem ser considerados os equipamentos do tipo, smartphones, tablets, Ipads, notebooks e televisão do tipo smart tv.

Nesse sentido, acredita-se na relevância em esclarecer esse conceito para obter subsídios teóricos a fim de planejar e desempenhar atividades práticas escolares com eles. Assim, Sonego e Behar (2015, p.522) afirmam que os dispositivos móveis são aparelhos "portáteis e conectados em rede, na qual, os envolvidos (professores e estudantes) tanto podem procurar informações, como receber e compartilhar a mesma". No entanto, considerase que, a partir de novas leituras, experiências e práticas escolares das autoras, esse conceito pode ser remodelado. Dessa forma, as autoras consideram pertinente delimitar dispositivos para o uso de smartphones e tablets. Essa demarcação deve-se ao fato de observar e perceber que esses aparelhos são os mais utilizados nos ambientes escolares e no dia a dia dos indivíduos. Além disso, são de fácil acesso, considerando as inúmeras ofertas no mercado, às diversas marcas, assim como o tamanho, a agilidade para manuseio, as telas do tipo touchscreen, e a navegabilidade em redes de internet do tipo $3 \mathrm{G}$ e $4 \mathrm{G}$. Assim posto, as autoras definem dispositivos móveis como, aparelhos digitais que possibilitam a mobilidade e a conectividade a fim de oportunizar a busca por informações, criação e compartilhamento de conteúdos, tendo como exemplo os smartphones e tablets.

Desse modo, percebe-se que os dispositivos móveis proporcionam diversas possibilidades para aprendizagem. Diante desse contexto, observa-se que existe a necessidade de planejar e desenvolver atividades escolares, incluindo os dispositivos móveis, considerando-se que esse tipo de aprendizagem oportuniza aos estudantes construir e aprimorar conhecimentos, desde que tenha em mãos um smartphone ou tablet e esteja conectado com a internet.

Conforme Leite (2014), o m-learning é capaz de ocorrer em distintas ocasiões em que os estudantes podem aproveitar para obter vantagem das tecnologias móveis. Entretanto, pondera-se que o fato de utilizar um dispositivo móvel para desempenhar uma atividade isolada em aula pode não se caracterizar como m-learning. Para tal fim, no desenvolvimento desse tipo de aprendizagem é necessário que a atividade proposta seja oriunda de um planejamento que envolva um conteúdo curricular, material didático e uma atividade de estudo orientada e guiada por um professor com objetivos educacionais.

Nessa perspectiva, percebe-se que o m-learning juntamente com os dispositivos móveis apresentam possibilidades de inovação no processo de ensino e de aprendizagem, oportunizando situações desafiadoras tanto para os professores quanto para os estudantes. Diante do exposto, considera-se que a aprendizagem móvel disponibiliza para os sujeitos envolvidos no seu processo, condições para "usar aparelhos móveis para acessar recursos educacionais, conectar-se a outras pessoas, criar conteúdos, dentro ou fora da sala de aula" (ORGANIZAÇÃO DAS NAÇÕES UNIDAS PARA A EDUCAÇÃO, CIÊNCIA E CULTURA, 2014, p.7). Esse processo ocorre devido aos seus recursos que permitem não só o acesso a materiais prontos, mas a possibilidade para criação e compartilhamento deles. Contudo, disponibiliza várias funcionalidades como, por exemplo, fotografar, gravar, executar vídeos e áudios, fazer downloads, anotações, editar textos, transferir dados, acessar páginas da internet entre outras funções. Desse modo, oportunizam planejar atividades de estudo que venham expandir a interação entre os envolvidos em todo o seu processo educativo.

Nesse sentido, destaca-se que a todo o momento surgem novas tendências em tecnologias. Com isso, são verificadas novas demandas dos alunos, para que o uso dos dispositivos seja efetivado através de atividades escolares. Salienta-se que os aplicativos, são exemplos a serem citados como uma tendência que pode ser utilizada como um recurso pedagógico e tecnológico. Esses dispõem de várias possibilidades no âmbito educacional para tentar atender as características da atual geração conectada.

Os aplicativos são programas elaborados exclusivamente para os dispositivos móveis do tipo smartphones e tablets (SANTOS; FREITAS, 2015). Atualmente, existem diversos App disponíveis na internet, de distintas áreas de conhecimentos, esporte, lazer, entretenimento e outras que podem ser encontrados facilmente nas lojas da Google Play (com aproximadamente 3,5 milhões) ou da Apple Store (com 2,2 milhões) de aplicativos (STATISTA, 2017). Nessas lojas virtuais, é possível fazer o download deles para os dispositivos conforme a necessidade de uso de cada indivíduo.

Além dos App disponíveis narede, existea possibilidade de construir aplicativos, tanto por professores quanto por estudantes ou demais interessados pelo assunto. Para tanto, na web, encontram-se ferramentas online que permitem essa elaboração. São softwares em versões free, ou seja, livre, que possibilitam aos envolvidos superarem desafios e possibilidades para a execução de App. Desse modo, conta-se com a Fábrica de Aplicativos $^{2}$, uma plataforma com diversas funcionalidades para criar um App, tanto de modo individual quanto colaborativo. Outra alternativa viável para elaborar aplicativos, é o Appy Pie ${ }^{3}$ (com características semelhantes ao exemplo anterior, porém apresenta alguns destaques como a capacidade de

\footnotetext{
2 Disponível em: http://fabricadeapliactivos.com.br. Acesso em :20 ago. 2019.

3 Disponível em: http://ptsnappy.appupie.com. Acesso em: 20 ago. 2019.
} 
revisões em tempo real, envio de notificações, localização por GPS, integração de redes sociais, sites, áudios, vídeos, rádio, entre outros. Cabe ressaltar que ambas potencializam a construção de $A p p$ sem conhecimentos prévios de informática, pois a sua interface é considerada intuitiva, auxiliando os usuários.

Por fim, tem-se o App Inventor ${ }^{4}$, um software desenvolvido pela universidade americana de Massachusetts Institute of Technology (MIT). Ele oportuniza construir aplicativos somente para o sistema Android e requer conhecimentos de programação computacional. Já os exemplos citados anteriormente, estão disponíveis para Android, Windows e iOS. Após a conclusão de um App, independente do software escolhido, o usuário pode fazer o download através de um link ou da leitura de QRcode para instalá-lo em um dispositivo móvel.

Nesse sentido, percebe-se que um aplicativo pode apresentar inovações nas práticas docentes, com possibilidades de pesquisa, escrita, leitura, construção de conteúdo, além de seu compartilhamento entre os envolvidos nesse processo. Além disso, o desenvolvimento de App torna-se uma alternativa para o uso dos dispositivos em aula, oportunizando novas formas de aprendizagens e aproximação entre os estudantes pertencentes a uma geração conectada e o ambiente escolar.

\section{FORMAÇÃo dE PROFESSORES VOLTADA PARA UMA GERAÇÃO CONECTADA}

A formação de professores na atualidade deve ir além da inclusão das tecnologias digitais, perpassando pelo uso e exploração dos dispositivos móveis. Os docentes presenciam nas escolas e na sociedade a utilização frequente e assídua dos smartphones e tablets pelos alunos e demais indivíduos. Com isso, verifica-se que a cada dia a internet possibilita que as pessoas estejam conectadas vinte e quatro horas por dia, com liberdade de expressão para as suas opiniões, a produção de conteúdo e a sua disponibilização na rede (KIUCHI; SILVA; GOMES, 2018).

Desse modo, torna-se relevante que a formação de professores também perpasse por transformações ao longo dos anos. E, dessa forma, oportunize a inclusão dos dispositivos móveis com o intuito de ofertar possibilidades de uso desses aparelhos nas escolas, fazendo-o com fins educacionais. Entretanto, essa integração também está atrelada ao fato de o público pertencente às escolas ser oriundo de uma geração conectada. Desse modo, Kiuchi, Silva e Gomes (2018) consideram que os jovens que nasceram a partir do ano de 1995 são próprios de

\footnotetext{
4 Disponível em: http://appinventor.mit.edu/explore. Acesso em: 20 ago. 2019.
}

uma época em que a internet estava sendo amplamente disseminada, utilizada e expandida pelos pertencentes a essa geração conectada.

Portanto, pode-se dizer que esses jovens são provenientes de um conjunto de pessoas da mesma época, que são caracterizados por apresentarem as suas ideias, expressão, serem formadores de opinião, autônomos e autores de conteúdo com potencial de ser explorado e divulgado na internet.

Nessa perspectiva, Sousa-Pereira, Leite e Melo Carvalho (2015) abordam que a formação de professores assume o papel de um agente que oportuniza transformações no meio educacional. Essas alterações são com o intuito de responder aos desafios sociais colocados pelas mudanças permanentes e acelerada do meio em que se está inserido, incluindo as tecnologias contemporâneas que se fazem presente.

Com base na Lei de Diretrizes e Bases da Educação Nacional (no 9.394, de 20 de dezembro de 1996), a formação inicial de professores para atuarem na educação básica está amparada artigo 62, que pontua:
A formação de docentes para atuar na educação básica far-se-á em nível superior, em curso de licenciatura, de graduação plena em universidades e institutos superiores de educação, admitida, como formação mínima para o exercício do magistério na educação infantil e nas quatro primeiras séries do ensino fundamental, a oferecida em nível médio, na modalidade Normal (BRASIL, [1996]).

Assim, compreende-se que a formação inicial de professores se refere à condição de formar profissionais com capacidade para atuar nos dois níveis da Educação Nacional. Por outra forma, na educação básica e de ensino superior, atendendo às expectativas dos estudantes e contribuindo para a qualificação das condições de trabalho e formação destes sujeitos.

Neste sentido, nota-se que a formação inicial dos professores tem sido um grande desafio para as políticas educacionais. Assim, deve-se buscar amparo em documentos legais que apoiam e incentivam a formação de professores a fim de amenizar e diminuir problemas no âmbito educacional, associados aos processos de ensino e aprendizagem da educação básica. Esses problemas estão diretamente relacionados com a formação dos professores que ministram aulas na educação básica. De outro modo, percebe-se que ainda existe um distanciamento da realidade com a meta 15 traçada pelo Plano Nacional de Educação (PNE) com vigência entre 2014-2024, referente à formação de professores.

Meta 15: garantir, em regime de colaboração entre a União, os Estados, o Distrito Federal e os Municípios, 
no prazo de 1 (um) ano de vigência deste PNE, política nacional de formação dos profissionais da educação de que tratam os incisos I, II e III do caput do artigo 61 da Lei no 9.394, de 20 de dezembro de 1996, assegurado que todos os professores e as professoras da educação básica possuam formação específica de nível superior, obtida em curso de licenciatura na área de conhecimento em que atuam (BRASIL, [2014]).

Considera-se que, com apoio do PNE, sejam ofertadas novas vagas para os professores da educação básica em nível superior, nas áreas de conhecimento em que os docentes já atuam nas escolas da rede pública ou privada (BRASIL, [2014]). No entanto, seguindo a linha de pensamento de Piaget (1972), em que o autor menciona que não se torna relevante aumentar o número de vagas na formação inicial, se não se focar na discussão da qualidade da educação oferecida. Entende-se que essa qualidade perpassa pela formação do professor e pelo comprometimento que ele deve ter com o seu aluno, priorizando o desenvolvimento do seu processo de aprendizagem e da formação dele como sujeito ativo e participativo na sociedade. Para tanto, faz-se necessário que o professor conheça o seu aluno, o contexto, a comunidade escolar a fim de obter subsídios para contribuir nesse processo.

Nessa perspectiva, acredita-se que seja relevante que os futuros professores se envolvam no conhecimento, exploração e manuseio das tecnologias digitais, como os dispositivos móveis, durante a formação inicial para que essas informações façam parte, posteriormente, das atividades e práticas docentes no cotidiano escolar. Compreende-se que essas tecnologias cada vez mais avançam em direção aos ambientes educacionais e, com isso, almeja-se que os professores tenham entendimento sobre elas para poder incorporá-las nas suas práticas na sala de aula.

Os adolescentes que estão atualmente nas escolas são usuários que admitem estarem conectados aos dispositivos móveis, deixando de lado o uso de computadores, TVs inteligentes e outros equipamentos em prol desses aparelhos (BARBOSA, 2016). Entende-se que esse fator esteja intimamente ligado ao fato de os dispositivos ofereceram fácil acesso à internet, apresentarem-se com custo acessível para a maioria da população, fácil utilização e por serem portáteis, posto que cabem na palma da mão. Considera-se significativo o fato de possuírem conexão com a internet do tipo wifi, $3 \mathrm{G}$ ou $4 \mathrm{G}$ possibilitando a realização de atividades do cotidiano e do meio escolar.

Diante desse contexto, percebe-se que os alunos da atual sociedade se diferenciam dos estudantes de uma ou até duas décadas atrás em relação ao uso das tecnologias digitais que também são conduzidas até a escola de forma expansiva. Em conformidade com essa questão, Sibilia (2012) aborda que existe uma divergência de épocas e, nesse sentido, é possível diagnosticar que existe um distanciamento entre os alunos do mundo atual e os ambientes escolares. Desse modo, essa desigualdade está relacionada com os avanços das gerações que vêm se constituindo ao longo dos anos. Para Twenge (2017), os jovens e adolescentes que hoje frequentam as escolas são considerados pertencentes a uma geração conectada, pelo fato de utilizarem os dispositivos o tempo todo para comunicação, entretenimento, produção de conteúdos, conforme seus objetivos pessoais (Figura 1).

Figura 1 - Características da geração conectada

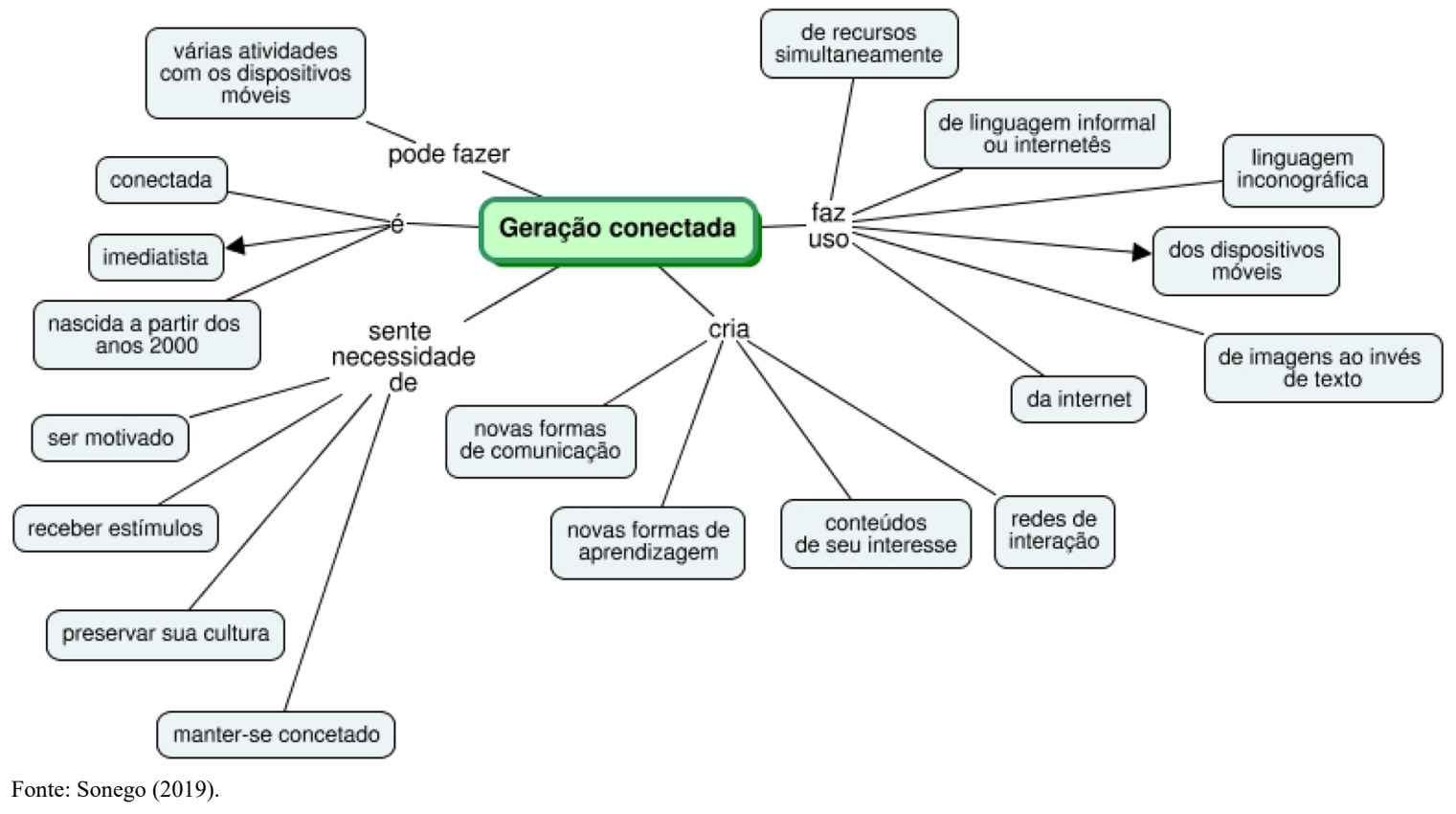

Educação (Porto Alegre), v. 42, n. 3, p. 514-524, set.-dez. 2019 
A Figura 1 tem o propósito de contribuir no entendimento do púbico que configura a geração conectada. Nesse sentido, Lluna e Garcia (2017), apontam que é uma geração formada por indivíduos que nasceram em meados dos anos noventa 2000. Desse modo, são sujeitos que não se imaginam viver e realizar atividades sem o uso das tecnologias digitais.

Para tanto, admite-se que existe uma necessidade e viabilidade na reformulação das práticas docentes a partir do uso dos dispositivos móveis nos ambientes educacionais. Sendo assim, essa reestruturação pode estar relacionada à organização pedagógica de cada professor, bem como à decisão do momento apropriado para o desenvolvimento do m-learning. Desse modo, espera-se que essa aprendizagem associada a um planejamento docente possa potencializar o processo de ensino e de aprendizagem dessa geração, explorando os dispositivos móveis nas suas mais diversas funcionalidades.

\section{Metodologia}

Esta pesquisa foi realizada a partir de um estudo de caso com uma abordagem qualitativa e quantitativa. Para tanto, participaram alunos oriundos de uma disciplina obrigatória de 45 horas, na modalidade presencial do curso de Pedagogia em uma universidade pública localizada no Rio Grande do Sul. O estudo foi realizado durante o segundo semestre de 2018 e o primeiro semestre de 2019, totalizando 60 alunos (30 em cada). A escolha dos participantes ocorreu devido à necessidade de uma abrangência maior de investigação sobre o tema m-learning e o uso dos dispositivos móveis na educação. Nessa perspectiva, levou-se em consideração que o assunto é contemporâneo e traz consigo muitos desafios e possibilidades para o planejamento e implementação de atividades escolares para um público jovem e conectado. Os professores que vivenciam essas situações na formação inicial podem apropriar-se de experiências e, futuramente, executá-las na sala de aula com alunos pertencentes a uma geração conectada. Além disso, esse curso de formação inicial de professores tem como propósito, desde os primeiros semestres, incluir conteúdos e recursos tecnológicos, como smartphones e tablets. Estes podem ser utilizados tanto na formação quanto nas práticas docentes na realização de atividades que envolvam a participação de uma geração conectada.

Durante o presente estudo, houve a realização das atividades em um Ambiente Virtual de Aprendizagem (AVA) em que os estudantes o utilizaram como suporte para a disponibilização de materiais, postagem dos trabalhos propostos e para os momentos de interação entre os participantes, como em fóruns de discussão. Dentre as atividades realizadas pelos alunos, destaca-se a construção de aplicativos educacionais, mantendo uma relação entre temáticas de interesse dos alunos com as tecnologias digitais. Esses App foram criados de forma individual a partir da ferramenta online AppyPie, que disponibiliza um espaço para essa tarefa sem a exigência de conhecimentos sobre programação.

A disciplina foi organizada em 15 aulas para cada semestre, onde foram incluídas atividades para serem realizadas na modalidade presencial e a distância. Foram abordadas temáticas relacionadas com o uso das tecnologias, as práticas pedagógicas, a formação inicial de professores, os dispositivos móveis e os aplicativos educacionais, a elaboração de página web, a construção de vídeos e áudios, a escrita coletiva, entre outras atividades.

Os dados oriundos da pesquisa foram organizados de acordo com a observação participante, com as questões que se fizeram mais relevantes e presentes nos extratos analisados referentes a um questionário com perguntas abertas e fechadas e, também, em relação à construção de aplicativos.

Para tanto, houve a necessidade de utilizar alguns instrumentos de pesquisa como a utilização de um ambiente virtual de aprendizagem com ênfase para as ferramentas de fórum, webfólio (de postagem de atividades), diário de bordo (de postagens menos formais, demonstrando dúvidas e perspectivas quanto aos assuntos estudados e atividades propostas) e questionário com perguntas abertas e fechadas.

\section{DisCUSSÃo DOS RESULTADOS}

No decorrer dos dois semestres foram realizadas atividades que ajudaram na construção dos aplicativos e para auxiliar o desenvolvimento do m-learning. Para tanto, houve a necessidade de implementar um questionário online ${ }^{1}$ para conhecer o que os estudantes sabiam sobre dispositivos, aprendizagem móvel e uso de App como um recurso educacional. Diante deste contexto, considera-se relevante ponderar os conhecimentos prévios dos estudantes sobre $m$-learning, bem como, oportunizar condições para reformular e criarem os seus significados para, posteriormente, desempenhar atividades práticas que venham necessitar desses como subsídios teóricos e, em seguida, os práticos.

Desse modo, a elaboração de aplicativos com base nos conceitos abordados em aula, pode potencializar o desenvolvimento de aspectos crítico, criativo, pedagógico e técnico na realização das atividades que os envolvam o uso de dispositivos móveis.

Quanto ao conceito de m-learning, os participantes mencionaram seu posicionamento e entendimento, conforme os seguintes extratos destacados: "seria uma aprendizagem móvel, um modo de se estudar a distância" 
(informação verbal). Já o estudante Y salientou que "é o ensino a distância através de dispositivos móveis" (informação verbal). Outro aluno respondeu que "Também chamado de aprendizagem móvel. É a utilização dos meios digitais a favor do aprendizado, como, por exemplo, videoaulas e livros digitais" (informação verbal). Diante dessas considerações, pode-se perceber que os estudantes do curso de graduação associam o m-learning com educação à distância. Isso é preocupante no que tange à realidade atual das escolas, que apresentam um público de adolescentes conectados.

Esse público refere-se aos alunos que possuem e utilizam diariamente os dispositivos móveis. De acordo com Lluna e Garcia (2017), são jovens que nasceram e convivem com as tecnologias digitais em rede, como um recurso do seu cotidiano e carregam seus dispositivos móveis para dentro do ambiente escolar. Compreende-se que o $m$-learning pode oferecer tanto ao professor, quanto ao aluno condições para gerar situações inovadoras para a construção e aprimoramento dos conhecimentos, quanto "para promover a comunicação e interação on-line entre sujeitos e destes com o seu contexto" e qualquer hora e lugar (SACCOL; SCHLEMMER; BARBOSA, 2011, p.2). Sendo assim, este tipo de aprendizagem pode apresentar condições viáveis para tornar as informações disponíveis e onipresentes no âmbito educacional.

Desse modo, acredita-se que os futuros professores devam vivenciar situações que envolvam atividades com o m-learning durante a sua formação. Com isso, terão possibilidades para experimentar, explorar e criar conteúdos a partir dos dispositivos, com vistas a perceber e reconhecer a diferença entre educação a distância e aprendizagem móvel. Desse modo, o docente poderá escolher o melhor momento para planejar e implementar tarefas que envolvam a aprendizagem escolhida de acordo com o contexto, o público, a estrutura e os equipamentos disponíveis. Compreende-se que somente com o conhecimento e a propriedade acerca de um tema e o tipo de aprendizagem que se pode decidir e escolher a melhor estratégia de ação para desenvolvê-la em sala de aula.

Associado ao conceito de aprendizagem móvel faz-se necessário ter a compreensão de que, para a sua realização, é primordial contar com os dispositivos móveis. Neste sentido, foi questionado aos estudantes o que eles entendem sobre dispositivos móveis, conforme mostram os extratos a seguir, "é um aparelho móvel" (estudante A), já o estudante $B$ "são dispositivos portáteis que você pode levar para qualquer lugar, não necessitando de conexão com fios". Outro estudante disse que "são dispositivos que acessam a internet e permitem comunicação e interação, ao mesmo tempo em que são facilmente transportáveis e portáteis". Percebe-se que os alunos possuem conhecimento sobre o que é dispositivo móvel, destacando suas principais características como a mobilidade, a conectividade e a portabilidade.

A compreensão desse termo pode auxiliar no entendimento e desenvolvimento do m-learning e saber lidar com a atual geração de adolescentes conectados. Desse modo, os dispositivos móveis apresentam-se com o propósito de promover o uso das tecnologias como ferramenta que fomente o processo de ensino e aprendizagem. De acordo Carr (2011 apud LIRA; PEREIRA; FELLl, 2017), a internet é uma das ferramentas tecnológicas mais utilizadas e carrega no seu cerne um alto potencial para atrair os seus usuários com suas distintas possibilidades de uso. Este fato está relacionado com a redução do tamanho para formatos portáteis, que cabem na palma da mão, em relação ao tamanho dos computadores.

Nesse sentido, a UNESCO (2014), apoia e incentiva o uso dos dispositivos móveis no dia a dia escolar, tendo em vista que eles estão ganhando cada vez mais espaço nesses ambientes devido suas diversas possibilidades. Além disso, é preciso saber manusear, explorar, criar conteúdo com esse tipo de aparelho. Para tanto, o professor que pretende disponibilizar atividades deve ter conhecimento. Desse modo, as tarefas podem ser desempenhadas dentro e fora do ambiente escolar, desenvolvendo o m-learning, em que os uso de equipamentos podem contribuir para ultrapassar as paredes da escola, fortalecendo o processo de ensino e aprendizagem dos estudantes (SIBILIA, 2012).

Entretanto, compreende-se que o uso dos dispositivos móveis são uma realidade dentre a atual geração, possibilitando o desenvolvimento da $m$-learning de forma significativa para os alunos. Além disso, existe uma gama de App que podem ser utilizados como recurso tecnológico potencializando o processo de ensino e aprendizagem dos estudantes. Diante deste contexto, buscou-se através do questionário saber o que os alunos entendiam sobre o termo aplicativos. Também se verificou que um dos estudantes respondeu que é "um software utilizado em dispositivos móveis" (estudante X). Outro sinalizou que "são softwares para celular que têm o intuito de executar determinada tarefa, por exemplo, aplicativos de jogos, ou de edição de fotos, ou de troca de mensagens". Os estudantes entendem que os aplicativos são programas que auxiliam os usuários a desempenharem determinada tarefa. Com isso, acredita-se que eles podem proporcionar condições para uma aprendizagem contínua e móvel. Conforme Krimberg et al. (2017), estes apresentam-se com potencial para promover inovação, interatividade e desenvolver de atividades em diversos formatos contribuindo para a construção do conhecimento dos alunos dentro e fora da escola. Para tanto, no âmbito educacional, eles devem ser utilizados associados a um 
planejamento, juntamente a conteúdos curriculares e atividades de estudo e não como um recurso isolado.

Sendo assim, espera-se que o uso dos App possa ampliar o alcance dos estudantes em relação ao desenvolvimento da aprendizagem e de conhecimentos abordados através dos aplicativos. Além disso, Ribeiro (2018) destaca que devem ser respeitadas as características de usabilidade para o desenvolvimento ou manipulação de um App. Para tanto, considera-se que os aplicativos precisam ser planejados e executados levando em conta que sua utilização ocorre através dos dispositivos móveis. Nesse sentido, devem ser apresentados de forma responsiva, possibilitando uma adequação ao tamanho da tela do aparelho móvel que está utilizando.

Após o questionário, os alunos tiveram como atividade o desenvolvimento dos seus próprios aplicativos educacionais, com base nos conceitos estudados e elaborados a partir das atividades anteriores. A construção destes App ocorreu através da relação das temáticas de interesse dos futuros professores com as tecnologias digitais em rede. Essa atividade proporcionou diversas formas para o desenvolvimento de conhecimentos, o compartilhamento de informações e conteúdo, a interação e a comunicação em qualquer tempo, em qualquer lugar.
Neste artigo são apresentados três exemplos (Figuras 2, 3 e 4) de App elaborados a partir da ferramenta Appy Pie durante a oferta de uma disciplina obrigatória do curso de Pedagogia em 2018/2 e a mesma foi replicada em 2019/1, como forma de exemplificar a prática dos estudos realizados. O aplicativo (Figura 2) foi elaborado, com o objetivo de explorar e conhecer um dos principais bairros da cidade de Porto Alegre. Nesse sentido, o App pretende auxiliar os estudantes e demais indivíduos a conhecer o que o bairro oferece como, por exemplo, escolas, postos de saúde, centro policial e outros locais de apoio à população.

O aplicativo apresentado na Figura 3 foi criado com o objetivo de informar os alunos que participam do Programa Aprendiz da Associação Canoense de Deficientes Físicos (Acadef), com informações atualizadas e com lembretes acerca dos trabalhos que estão sendo desenvolvidos no grupo.

O terceiro exemplo (Figura 4) é um aplicativo que foi desenvolvido de forma interdisciplinar das disciplinas de geografia, artes e filosofia e que apresenta como objetivo, auxiliar os alunos com informações e matérias de apoio com referência as disciplinas que orientam o aplicativo. $\mathrm{O}$ mesmo, ainda apresenta atividades que permitem o desenvolvimento da m-learning a fim de ampliar as formas de aprendizagens dos estudantes.
Figura 2 - Aplicativo Bairro Alegre

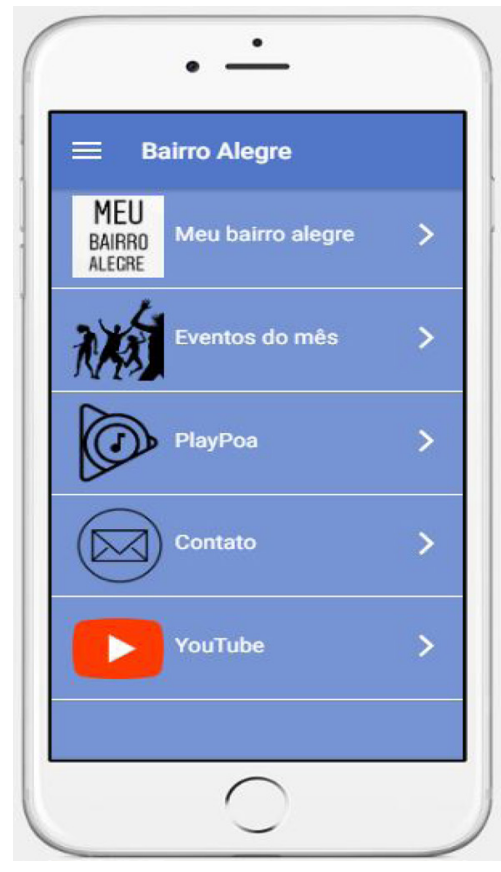

Fonte: Site Fábrica de Aplicativos. ${ }^{5}$
Figura 3 - Aplicativo Aprendiz ACADEF

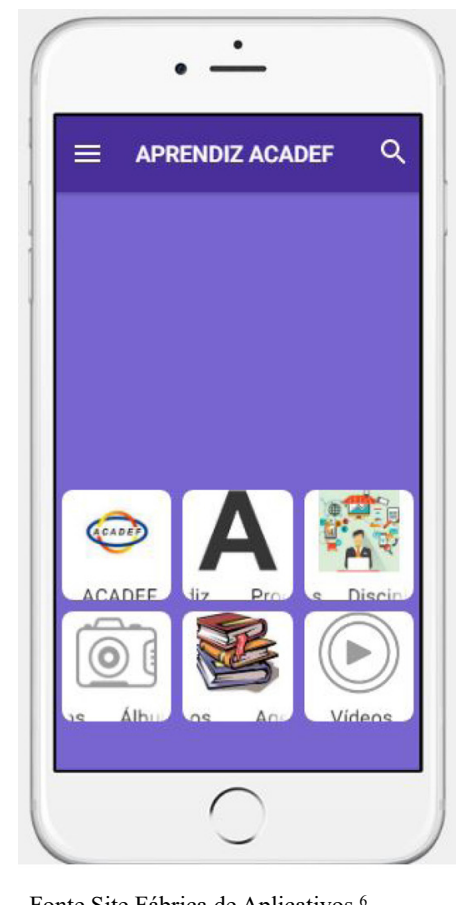

Fonte Site Fábrica de Aplicativos. ${ }^{6}$

\footnotetext{
5 Imagem capturada no site Fábrica de Aplicativos. Disponível em: https:/www.pwastore.com/w/gafeduca\%C3\%A7\%C3\%A3o-89bf2ce90903. Acesso em: 26 ago. 2019.

${ }^{6}$ Imagem capturada no site Fábrica de Aplicativos. Disponível em: https://galeria.fabricadeaplicativos.com.br/aprendiz_acadef. Acesso em: 26 ago. 2019.
} 
Figura 4 - Aplicativo GAF.Educação

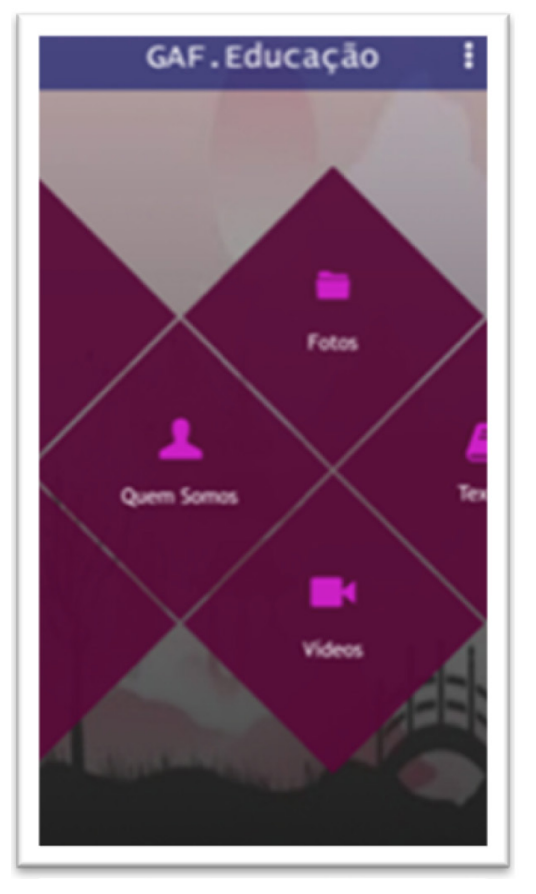

Fonte: Site Fábrica de Aplicativos. ${ }^{7}$

Nessa atividade, os alunos realizaram, inicialmente, um planejamento para a construção do aplicativo, envolvendo o tema a ser desenvolvido para que eles se sentissem apropriados e motivados na elaboração da tarefa. Na sequência, os foram feitas pesquisas, leituras para obterem subsídios para a escrita e a construção de conteúdo, incluindo vídeos, áudios, textos e outros materiais que foram incluídos nos aplicativos. Foi salientada aos estudantes a importância em destacar os autores dos materiais utilizados, respeitando os direitos autorais deles. Esse cuidado deve ser tomado, levando em conta a distribuição dos aplicativos, pois estarão expostos na internet para qualquer pessoa do mundo acessar e fazer o download no seu dispositivo móvel para usufruir as suas potencialidades e funcionalidades.

Desse modo, considera-se que essa atividade de construção de um App pode oportunizar diversas contribuições na aprendizagem dos estudantes a partir das funcionalidades e recursos disponíveis nos smartphones e tablets, potencializando o desenvolvimento do m-learning.

Ainda sobre o termo aprendizagem móvel, analisou-se o posicionamento dos futuros professores quanto às possibilidades para o desenvolvimento de atividades com os dispositivos móveis com os seus alunos, conforme os extratos a seguir, pode ser visto que "acharia

\footnotetext{
7 Imagem capturada no site Fábrica de Aplicativos. Disponível em: https:// www.pwastore.com/w/gafeduca\%C3\%A7\%C3\%A3o-89bf2ce90903. Acesso em: 26 ago. 2019.
}

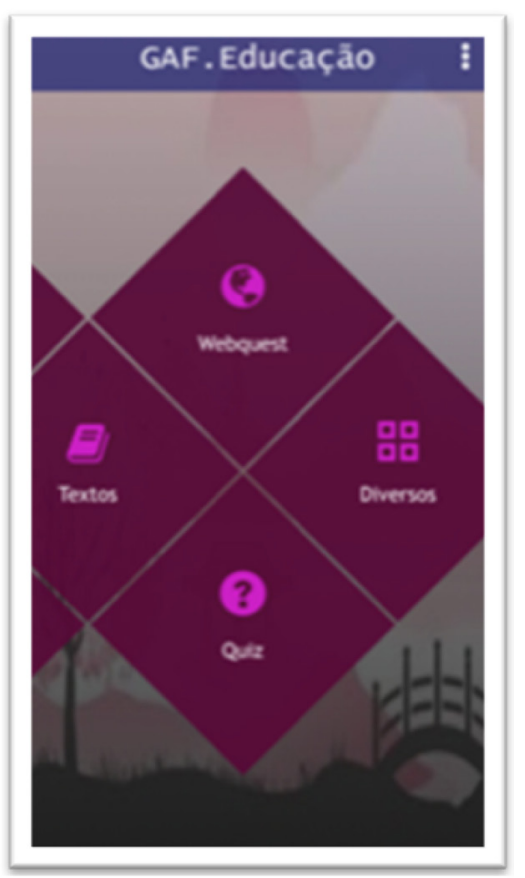

interessante realizar aulas no ambiente EAD, caso o Professor não puder comparecer nas aulas presenciais, isso é um mediador tanto para os professores quanto para os alunos" (estudante C). Outro estudante mencionou que o "o uso dessas ferramentas é indispensável hoje em dia. Se, desde cedo, fosse ensinado aos alunos que a tecnologia pode ser usada a favor da sua aprendizagem, acho que teríamos mais alunos capacitados a desenvolver suas próprias atividades, bem como realizá-las com menos burocracia".

Nesse sentido, pode-se dizer que os futuros professores pretendem elaborar atividades que desenvolvam m-learning nas suas ações docentes. Assim posto, destaca-se a relevância em realizar um planejamento com objetivos definidos de acordo com a faixa etária dos alunos, a fim de potencializar o processo de ensino e de aprendizagem dos envolvidos.

Acredita-se que essa possibilidade revelada pelos pesquisados em relação ao desenvolvimento do m-learning pode estar associada ao fato deles passarem, no decorrer da disciplina, por atividades propostas que envolvessem o uso dos dispositivos móveis. Para tanto, destaca-se que quando "utilizados de forma correta o celular pode contribuir para o desenvolvimento de uma aprendizagem significativa" (VIVIAN; PAULY, 2012, p.4). Sendo assim, esse uso está relacionado com o planejamento de aula, as estratégias pedagógicas empregadas pelo professor, a escolha do dispositivo e a estrutura de internet que a escola oferece. 
Além disso, a realização de atividades com os dispositivos móveis possibilita elaborar conteúdos, materiais educacionais e criar possibilidades para potencializar o processo de ensino e aprendizagem. Percebe-se que a inclusão dos dispositivos móveis nas escolas é uma realidade e uma possibilidade viável que acompanha a geração conectada. Para tanto, se faz necessário que o professor conheça e saiba manipular os aparelhos para que tenha subsídios e consiga elaborar atividades como, por exemplo, a construção de aplicativos. Essa tarefa oportuniza aos usuários novas formas de aprendizagem, de comunicação com capacidade para desafiar e motivar os sujeitos envolvidos nesse processo.

\section{CONSIDERAÇÕES FINAIS}

O objetivo deste artigo foi analisar a construção de aplicativos educacionais a fim de auxiliar o desenvolvimento do m-learning através do uso dos dispositivos móveis com estudantes de um curso de graduação em uma universidade pública.

Entretanto, percebe-se que este estudo se tornou viável pelo fato que, no atual cenário escolar, os estudantes, na sua maioria, são pertencentes a uma geração conectada, que utiliza os dispositivos móveis de modo espontâneo e diário no desempenho de várias tarefas, que vão desde a comunicação até potencialização do processo de ensino e de aprendizagem. Neste sentido, acredita-se que existe um leque de possibilidades para a realização de atividades com os smartphones e tablets, potencializando o desenvolvimento da m-learning. Contudo, para que isso aconteça, torna-se pertinente que, nos cursos de formação de professores, ocorram situações inovadoras que proporcione perpassar por situações de ensino e aprendizagem que vislumbrem a apresentação, a produção de conteúdos, de materiais de uma forma mais interativa e lúdica através desses dispositivos como, por exemplo, utilizando e criando aplicativos educacionais. Dessa forma, entende-se que o desenvolvimento de um App pode contribuir de maneira significativa, tanto para a formação de professores, quanto para a implementação de tarefas nas práticas dos docentes.

Além disso, para que essas tarefas sejam realizadas, esses futuros professores devem conhecer e apropriaremse de conceitos acerca dos termos m-learning, dispositivos móveis e aplicativos. Sendo assim, esperase criar possibilidades para compreender as suas relações e potencialidades no desenvolvimento do processo de ensino e aprendizagem dos jovens que pertencem à geração conectada, bem como, repensar novas práticas que permitam incluir os dispositivos de modo significativo no contexto educacional.

\section{REFERÊNCIAS}

BARBOSA, A. F. (coord.). Pesquisa sobre o uso das tecnologias de informação e comunicação no setor público brasileiro: TIC governo eletrônico 2015. São Paulo: Comitê Gestor da Internet no Brasil, 2016. Disponível em: https:// cgi.br/media/ docs/publicacoes/2/TIC_eGOV_2015_LIVRO ELETRONICO.pdf. Acesso em: 2 out. 2017. https://doi. org/10.17699/workshopnpt.13.11

BRASIL. Lei n⿳9.394, de 20 de dezembro de 1996. Estabelece as diretrizes e bases da educação nacional. Brasília: Presidência da República, 1996. Disponível em: http://www.planalto.gov.br/ccivil_03/leis/19394.htm. Acesso em: 9 jan. 2019. https://doi.org/10.11606/d.2.2017.tde03102017-105747

BRASIL. Lei $\mathbf{n}^{\mathbf{0}} \mathbf{1 3 . 0 0 5}$, de 25 de junho de 2014. Aprova o Plano Nacional de Educação - PNE e dá outras providências. Brasília: Presidência da República, 2014. Disponível em: http:/www.planalto.gov.br/ccivil_03/ ato2011-2014/2014/ lei/113005.htm. Acesso em: 9 jan. $201 \overline{8}$. https://doi. org/10.1590/1413-81232014198.06322014

CÓDIGO QR. In: WIKIPÉDIA: a enciclopédia livre. [San Francisco: Wikimedia Foundation], 2019. Disponível em: https://pt.wikipedia.org/wiki/C\%C3\%B3digo_QR. Acesso em: 17 out. 2019.

KIUCHI, C.; SILVA, J. O.; GOMES, L. R. R. Youtubers: a nova geração de influenciadores. Revista Científica UMC, Mogi das Cruzes, v. 3, n. 1, p. 1-14, 2018.

KRIMBERG, L. et al. Construção de aplicativos educacionais na formação de professores: critérios pedagógicos, técnicos e interativos. In: CONFERÊNCIA INTERNACIONAL SOBRE INFORMÁTICA NA EDUCAÇÃO, 13., 2017, Fortaleza. Anais [...]. Fortaleza: TISE, 2017. Disponível em: http://www.tise.cl/2017/img/ActasTISE2017.pdf. Acesso em: 18 jan. 2019. https://doi.org/10.17648/ciie-201797105

LEITE, B. S. M-Learning: o uso de dispositivos móveis como ferramenta didática no Ensino de Química. Revista Brasileira de Informática na Educação, Porto Alegre, v. 22, n. 3, p. 55-68, 2014. https://doi.org/10.5753/rbie. 2014.22.03.55

LIRA, J.; PEREIRA, M. K. S.; FELL, A. F. A. A geração superficial: o que a internet está fazendo com os nossos cérebros. Navus: Revista de Gestão e Tecnologia, Florianópolis, v. 7, n. 2, p. 124-129, 2017. https://doi. org/10.22279/navus.2017.v7n2.p124-129.512

LLUNA, S.; GARCIA, J. P. Introducción. In: LLUNA, S.; PEDREIRA, J. (ed.). Los nativos digitales no existen: Cómo educar a tus hijos para un mundo digital. Barcelona: Deusto, 2017. p. 27-31.

ORGANIZAÇÃO DAS NAÇÕES UNIDAS DO BRASIL. Brasil é o quarto país com mais usuários de Internet do mundo, diz relatório da ONU. Brasília: ONUBR, 2017. 
Disponível em: https://nacoesunidas.org/brasil-e-o-quartopais-com-mais-usuarios-de-internet-do-mundo-diz-relatorioda-onu/. Acesso em: 27 mar. 2018.

\section{ORGANIZAÇÃO DAS NAÇÕES UNIDAS PARA A} EDUCAÇÃO, CIÊNCIA E CULTURA. Diretrizes de políticas para aprendizagem móvel. Brasília: UNESCO, 2014. Disponível em: http://unesdoc.unesco.org/ images/0022/002277/227770por.pdf. Acesso em: 21 mar. 2019. https://doi.org/10.5212/praxeduc.v.12i2.0017

PIAGET, J. Para onde vai a educação? Rio de Janeiro: José Olympio, 1972.

QUINN, C. M-learning: mobile, wireless, in your pocket learning. LiNE Zine: [s. n.], 2000. Disponível em: http://www. linezine.com/2.1/features/cqmmwiyp.htm. Acesso em: 6 ago. 2018.

RIBEIRO, A. C. R. et al. Estratégias pedagógicas para a m-learning: um objeto de aprendizagem voltado para a formação de professores. In: CONFERENCIA IBEROAMERICANA DE COMPLEJIDAD, INFORMÁTICA Y CIBERNÉTICA: CICIC 2018, 8., 2018, Orlando. Anais [...]. Orlando: [s. n.], 2008. Disponível em: http://www.iiis.org/CDs2018/CD2018Spring/papers/ CB783NQ.pdf. Acesso em: 24 jun. 2019. https://doi. org/10.5151/16ergodesign-0019

SACCOL, A.; SCHLEMMER, E.; BARBOSA, J. M-learning e u-learning: novas perspectivas da aprendizagem móvel e ubíqua. São Paulo: Pearson Prentice Hall, 2011.

SANTOS, F. M. V.; FREITAS, S. F. Avaliação da usabilidade de ícones de aplicativo móvel utilizado como apoio educacional para crianças na idade pré-escolar. Ação Ergonômica: Revista da Associação Brasileira de Ergonômica, Rio de Janeiro, v. 10, n. 2, p. 123-132, 2015. https://doi.org/10.5151/15ergodesign-117-u004

SIBILIA, P. Redes ou paredes: a escola em tempos de dispersão. Rio de Janeiro: Contraponto, 2012. https://doi. org/10.1590/s1413-24782015206113

SONEGO, A. H. S. ARQPED-MOBILE: uma arquitetura pedagógica com foco na aprendizagem móvel. 2019. Tese (Doutorado em Educação) - Programa de Pós-Graduação em Educação, Faculdade de Educação, Universidade Federal do Rio Grande do Sul, Porto Alegre, 2019. https://lume.ufrgs.br/handle/10183/197443

SONEGO, A. H. S.; BEHAR, P. A. M-learning: reflexões e perspectivas com o uso de aplicativos educacionais. In: CONFERÊNCIA INTERNACIONAL DE SOBRE INFORMÁTICA NA EDUCAÇÃO, 20., 2015, Santiago. Anais Nuevas Ideas en Informática Educativa. Santiago: [ $s$. n.], 2015. Disponível em: http://www.tise.cl/volumen11/ TISE2015/521-526.pdf. Acesso em: 11 jun. 2018.

SOUSA-PEREIRA, F.; LEITE, C.; CARVALHO, J. M. Políticas de formação inicial de professores em Portugal no processo de Bolonha: uma análise intrainstitucional a partir de práticas de formação. Educação Unisinos, São Leopoldo, v. 19, n.1, p. 6-21, 2015. Disponível em: http://revistas. unisinos.br/index.php/educacao/article/view/edu.2015.191.01/ 4568. Acesso em: 15 jan. 2018. https://doi.org/10.4013/edu. 2015.191.01

STATISTA. [Site]. [S. l.: Statista, 2019]. Disponível em: https://www.statista.com. Acesso em: 3 jan. 2018. https://doi. org/10.5260/cca. 199318

TWENGE, J. M. iGen: why today's super-connected kids are growing up less rebellious, more tolerant, less happy and completely unprepared for adulthood. New York: Atria Books, 2017. https://doi.org/10.1177/1077695818758107

VALENTE, J. A. Blended learning e as mudanças no ensino superior: a proposta da sala de aula invertida. Educar em Revista, Curitiba, n. esp. 4, p. 79-97, 2014. Disponível em: http://www.scielo.br/pdf/er/nspe4/0101-4358-eresp-04-00079.pdf. Acesso em: 6 ago. 2018. https://doi. org/10.1590/0104-4060.38645

VALENTE, J. A. Relatório aponta Brasil como quarto país em número de usuários de internet. [S. l.]: Agência Brasil, 2017. Disponível em: http://agenciabrasil.ebc.com.br/geral/ noticia/2017-10/relatorio-aponta-brasil-como-quarto-pais-emnumero-de-usuarios-de-internet. Acesso em: 15 jan. 2018. https://doi.org/10.11606/t.48.2009.tde-23092009-135533

VIVIAN, C. D.; PAULY, E. L. P. O uso do celular como recurso pedagógico na construção de um documentário intitulado: Fala sério! Revista Digital da CVA, Ricesu, v. 7, n. 27, 2012.

Recebido em: 11/10/2018.

Aprovado em: 16/7/2019.

Publicado em: 5/11/2019.

Endereço para correspondência:

Anna Helena Silveira Sonego

Rua Paulo Gama, 110, prédio 12105, 4ㅇandar, sala 401

90040-060, Porto Alegre, RS, Brasil

\section{Autoras:}

AnNa Helena Silveira Sonego

Doutora em Educação pela Universidade Federal do Rio Grande do Sul (UFRGS). Pesquisadora na Universidade Federal do Rio Grande do Sul (UFRGS), Porto Alegre, RS, Brasil.

Orcid: http://orcid.org/0000-0002-9238-1327

E-mail: sonego.anna@gmail.com

Patricia Alejandra Behar

Doutora em Ciência da Computação pela Universidade Federal do Rio Grande do Sul (UFRGS). Docente adjunta na Universidade Federal do Rio Grande do Sul, Porto Alegre, RS, Brasil.

Orcid: http://orcid.org/0000-0001-6939-5678

E-mail: pbehar@terra.com.br 